Research Article

\title{
To study the pattern of suspected adverse drug reactions in patients coming to the department of dermatology in Gauhati Medical College and Hospital, Guwahati, Assam, India
}

\author{
Ajoy Borah $^{1} *$, Mangala Lahkar ${ }^{1}$, Binita Singha ${ }^{1}$, \\ Ratan J. Lihite ${ }^{2}$, Debeeka Hazarika ${ }^{3}$
}

\begin{abstract}
${ }^{1}$ Department of Pharmacology,
${ }^{2}$ ADR Monitoring Centre,

${ }^{3}$ Department of Dermatology

Gauhati Medical College,

Guwahati-32, Assam, India
\end{abstract}

Received: 15 June 2016

Accepted: 08 July 2016

*Correspondence to:

Dr. Ajoy Borah,

Email: ajoyborah47@

gmail.com.

Copyright: (C) the author(s), publisher and licensee Medip Academy. This is an openaccess article distributed under the terms of the Creative Commons Attribution NonCommercial License, which permits unrestricted noncommercial use, distribution, and reproduction in any medium, provided the original work is properly cited.

\begin{abstract}
Background: Cutaneous adverse drug reactions (ADRs) are the commonest ADRs (30-45\%) and are responsible for about $2 \%$ of hospital admissions. This study was conducted to study the pattern of ADRs coming to the department of dermatology in a Tertiary Health Care Hospital. The objectives of the study were to assess the causality, severity, preventability, age distribution, sex distribution and the reactions occurring.

Methods: Cross-sectional study. The suspected adverse drug reactions (ADRs) reported from the department of dermatology in the Spontaneous ADR reporting form was analysed in this study over a period of one year.

Results: A total of 513 cases of reported ADRs were analysed. The highest number of ADRs was reported in the Age group 21-40 years with female preponderance. Erythematous maculopapular lesions were the most common $\mathrm{ADR}$ and maximum cases of ADRs were observed with steroids. Most cases were found to be probable (causality assessment), of mild severity and were probably preventable.

Conclusions: The study showed that a number of drugs cause dermatological ADRs. These ADRs vary in their appearance, duration, causality, severity, and preventability.
\end{abstract}

Keywords: Cutaneous, Dermatology, Skin, Drug reactions, Pharmacovigilance

\section{INTRODUCTION}

Drugs, however safe and efficacious, are associated with inescapable risk of adverse reactions. Adverse Drug Reactions (ADRs) are one of the leading causes of morbidity and mortality. ${ }^{1}$ According to WHO, an adverse drug reaction is defined as "a response to a drug that is noxious and unintended and occurs at doses, used in man for prophylaxis, diagnosis, or therapy of a disease or for modification of physiological function. ${ }^{2}$ Consequences of ADRs range from diminished quality of life, increased physician visits, hospitalizations, and even death. In a study, ADRs was rated as the fifth leading cause of death among all diseases. Approximately $5-8 \%$ of all hospitalization worldwide is due to adverse drug reactions. ${ }^{3}$ Cutaneous ADRs are the commonest ADRs $(30-45 \%)$ and are responsible for about $2 \%$ of hospital admissions. ${ }^{4,5}$ Approximately $2-7 \%$ of these may be severe. ${ }^{5}$ The incidence of dermatological ADRs among in-patients in developed countries ranges from $1-3 \%$ whereas in developing countries such as India it is $2-5 \%$. The incidence of drug-induced adverse skin reactions is found to be $2-15 \%$ at a dermatology outpatient setting. ${ }^{6}$ Many ADRs are commonly known and are present in literature but some are rare and may present without warning. Cutaneous drug eruptions are one of the most 
common types of adverse reaction to drug therapy, with an overall incidence rate of $2-3 \%$ in hospitalized patients. ${ }^{7,8}$ This study was therefore conducted to study the pattern of ADRs coming to the department of dermatology in a tertiary health care hospital. The objectives of the study were to assess the causality, severity, preventability, age distribution, sex distribution and the reactions occurring.

\section{METHODS}

The study was carried out in the adverse drug reaction monitoring centre in the department of pharmacology, gauhati medical college.

The protocol was approved by the Institutional Ethics Committee of Gauhati Medical College and Hospital, Guwahati bearing approval no. MC/233/2013/106.

It was an observational study of cross sectional design. The Suspected adverse drug reactions reported from the department of dermatology in the spontaneous ADR reporting forms were analysed in this study.

The duration of this study was one year (March 2014 February 2015).

\section{Data analysis}

The suspected adverse drug reactions were assessed for causality, severity and preventability. Naranjo's scale was used for causality assessment, hart wig and Siegel's scale was used for assessment of severity and Schumock and Thornton's criteria was used to assess the preventability of the ADRs. ${ }^{9-11}$ The reactions were also assessed to find the sex distribution, age group distribution and pharmacological class wise distribution of the suspected adverse drug reactions. The total number of particular reactions was also calculated. All the data have been expressed in terms of percentage.

\section{RESULTS}

Table 1: Age distribution of adverse drug reactions coming to dermatology OPD.

\begin{tabular}{|lllll|}
\hline $\begin{array}{l}\text { Age } \\
\text { group }\end{array}$ & Males & Females & $\begin{array}{l}\text { Total } \\
\text { no. of } \\
\text { ADRs }\end{array}$ & $\begin{array}{l}\text { Percentage } \\
\text { of total } \\
\text { ADRs }\end{array}$ \\
\hline 0-10 years & 12 & 15 & 27 & $5.26 \%$ \\
\hline 11-20 years & 30 & 68 & 98 & $19.10 \%$ \\
\hline 21-40 years & 94 & 201 & 295 & $57.50 \%$ \\
\hline 41-60 years & 32 & 46 & 78 & $15.20 \%$ \\
\hline$>$ 60 years & 4 & 11 & 15 & $2.92 \%$ \\
\hline Total & $\mathbf{1 7 4}$ & $\mathbf{3 3 9}$ & $\mathbf{5 1 3}$ & \\
\hline & & & & \\
\hline
\end{tabular}

The results of the study have been expressed in Tables 1 , 2, 3, 4 and Figures 1, 2, 3, 4. A total of 513 cases of ADRs were reported during the period of the study. The highest number of ADRs was reported in the age group 21-40 years (295 cases, $57.50 \%$ of the total number of cases, Refer Table 1).

Table 2: Sex distribution of adverse drug reactions coming to dermatology OPD.

\begin{tabular}{|lll|}
\hline Sex & $\begin{array}{l}\text { Total no. of } \\
\text { ADRs }\end{array}$ & $\begin{array}{l}\text { Percentage of total } \\
\text { ADRs }\end{array}$ \\
\hline Male & 174 & $33.91 \%$ \\
\hline Female & 339 & $66.08 \%$ \\
\hline Total & 513 & \\
\hline
\end{tabular}

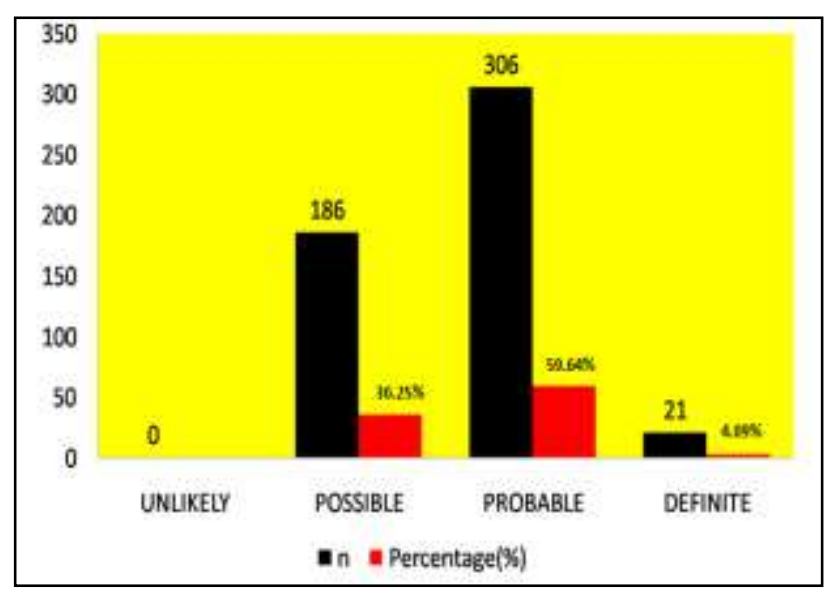

Figure 1: Causality assessment of the dermatological ADRs using Naranjo's scale ( $n$ = total number of cases).

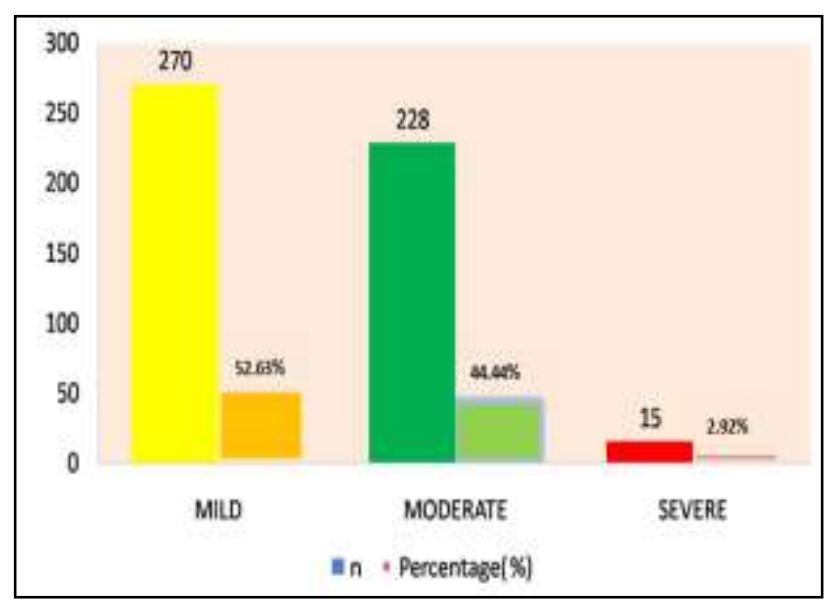

Figure 2: Severity assessment of the dermatological ADRs using Hart wig scale ( $n=$ total number of cases).

Female to male ratio of ADRs was found to be 2:1 (Table $1,2)$.

Erythematous maculopapular lesions were the most commonly reported ADR (165 cases, 27.48\%). 9 cases of SJS (Stevens Johnsons syndrome) and 3 cases of TEN (toxic epidermal necrolysis) were also reported (Refer Table 4 and Figure 4). 


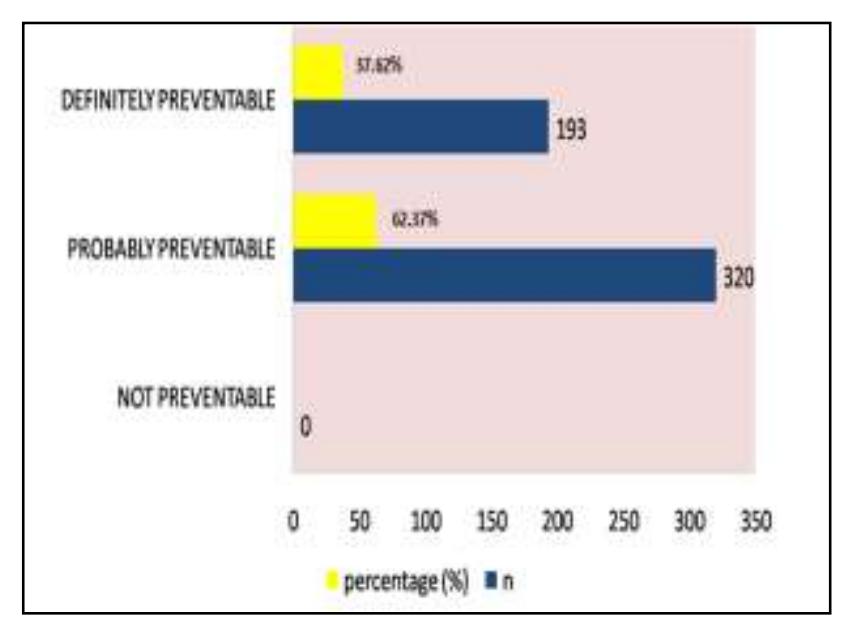

Figure 3: Assessment of the preventability of the dermatological ADRs using Schumock Thronton scale ( $n$ = total number of cases).

Table 3: Drug wise distribution of adverse drug reactions coming to dermatology OPD.

\begin{tabular}{|c|c|c|}
\hline Pharmacological class & $\begin{array}{l}\text { Total no. } \\
\text { of ADRs }\end{array}$ & $\begin{array}{l}\text { Percentage of } \\
\text { total ADRs }\end{array}$ \\
\hline Steroids & 378 & \multirow{3}{*}{$73.68 \%$} \\
\hline Topical & 323 & \\
\hline Prednisolone & 55 & \\
\hline Antimicrobials & 57 & \multirow{10}{*}{$11.1 \%$} \\
\hline Amoxicillin & 18 & \\
\hline Rifampicin & 15 & \\
\hline INH & & \\
\hline Lincomycin & 7 & \\
\hline Cephalosporin & 6 & \\
\hline Erythromycin & 4 & \\
\hline Clarithromycin & 3 & \\
\hline Amikacin & 2 & \\
\hline Terbinafine & 2 & \\
\hline NSAIDS & 27 & \multirow{6}{*}{$5.26 \%$} \\
\hline Paracetamol & & \\
\hline Paracetamol and & 15 & \\
\hline ibuprofen & 7 & \\
\hline Diclofenac & 3 & \\
\hline Aceclofenac & 2 & \\
\hline Antiepileptics & 15 & \multirow{3}{*}{$2.92 \%$} \\
\hline Carbamazepine & 9 & \\
\hline Phenytoin & 6 & \\
\hline OCPS & 9 & $1.75 \%$ \\
\hline Herbal medicines & 27 & $5.26 \%$ \\
\hline
\end{tabular}

Maximum incidence of dermatological ADRs were observed with Steroids (73.68\%, 378 cases) followed by Anti-Microbial agents (11.1\%, 57 cases), Non-steroidal Anti-inflammatory drugs (5.26\%, 27 cases), Antiepileptic agents $(2.92 \%, 15$ cases $)$, Oral contraceptive pills $(5.26 \%, 9$ cases). 27 cases $(5.26 \%)$ of ADRs were also reported due to intake of herbal medicines (Refer Table 3).

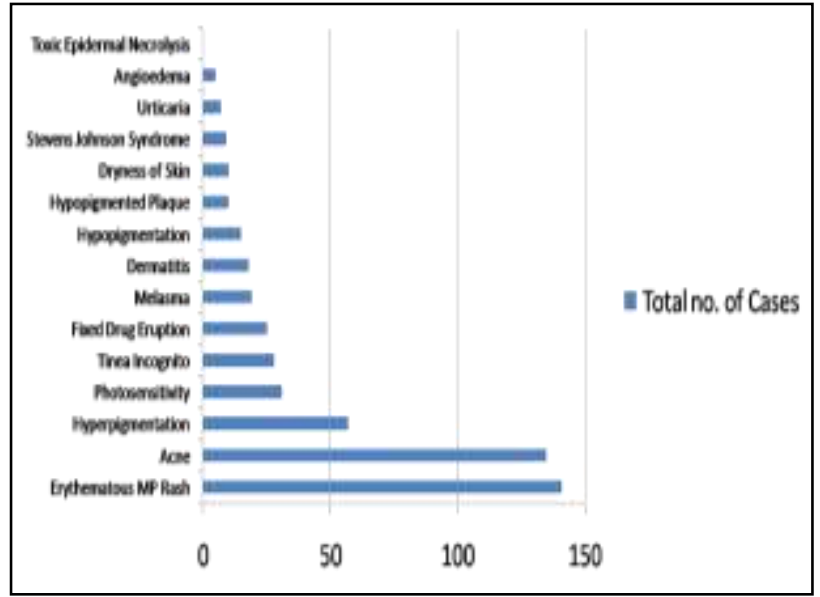

Figure 4: Reaction wise distribution of adverse drug reaction coming to dermatology department.

Table 4: Reaction wise distribution of adverse drug reactions coming to dermatology OPD.

\begin{tabular}{|lll|}
\hline Reactions & $\begin{array}{l}\text { Total no. } \\
\text { of ADRs }\end{array}$ & $\begin{array}{l}\text { Percentage of } \\
\text { total ADRs }\end{array}$ \\
\hline $\begin{array}{l}\text { Erythematous } \\
\text { maculopapular lesions }\end{array}$ & 141 & $27.48 \%$ \\
\hline Acne & 135 & $26.31 \%$ \\
\hline Hyperpigmentation & 57 & $11.11 \%$ \\
\hline $\begin{array}{l}\text { Photosensitivity } \\
\text { reactions }\end{array}$ & 31 & $6.04 \%$ \\
\hline Tinea incognito & 28 & $5.45 \%$ \\
\hline Fixed drug eruptions & 25 & $4.87 \%$ \\
\hline $\begin{array}{l}\text { Melasma/aggravation of } \\
\text { melasma }\end{array}$ & 19 & $3.70 \%$ \\
\hline Dermatitis & 18 & $3.50 \%$ \\
\hline Hypopigmentation & 15 & $2.92 \%$ \\
\hline Hypopigmented plaque & 10 & $1.94 \%$ \\
\hline dryness of skin & 10 & $1.94 \%$ \\
\hline $\begin{array}{l}\text { SJS (stevens johnson } \\
\text { syndrome) }\end{array}$ & 9 & $1.75 \%$ \\
\hline Urticaria & 7 & $1.36 \%$ \\
\hline Angioedema & 5 & $0.97 \%$ \\
\hline $\begin{array}{l}\text { Ten (topical epidermal } \\
\text { necrolysis) }\end{array}$ & 3 & $0.58 \%$ \\
\hline
\end{tabular}

Naranjo's scale showed most cases to be probable (306 cases, $59.64 \%$ ). 21 cases were found to be definitely caused by the suspected drug as re-challenge could be done in them (Figure 1).

Most of the ADRs were of mild severity (270 cases, $52.63 \%$ ), shown in Figure 2 and probably preventable (320 cases, $62.37 \%$ ), shown in Figure 3.

\section{DISCUSSION}

513 cases of Cutaneous ADRs were analysed in the study over duration of one year. Female predominance $(66.08 \%)$ was seen in this study. This is seen in 
accordance with studies conducted by Verma et al, Pudukadan et al and Chatterjee et al. ${ }^{12-14}$ This is however in contrast to studies where male predominance has been observed. $^{15,16} 57.50 \%$ cases of ADRs were in the age group 21-40 years, also reported by Verma et al, Sharma et al, Leape et al had also observed that adults aged 20-49 years were at greatest risk of antibiotics-related drug eruptions, probably due to increased exposure to antibiotics. $^{12,16,17}$ However, few studies have noted that the elderly are more commonly affected. ${ }^{18}$ Erythematous maculopapular lesions were the most commonly reported ADR in the study. Verma et al and Sharma et al also reported similar findings. ${ }^{12,16}$ Some other studies found fixed drug eruptions as the most common drug eruption followed by maculopapular rash and urticaria. ${ }^{19}$ In this study steroids were implicated with maximum number of ADRs. Mokhtari et al in his assessment of cutaneous ADRs over a period of 8 years found anticonvulsants and antibiotics to be the drugs responsible for most of the cutaneous ADRs. ${ }^{20}$ Most of the ADRs in this study were designated as probable in Naranjo's causality assessment which is consistent with Verma et al. ${ }^{12}$ Most of the ADRs were found of Mild severity which is in contrast to Verma et al and Gohel et al. ${ }^{1}$ This could be because this study included ADRs reported in the outpatients of dermatology along with inpatients of dermatology ward. Most of the ADRs were found to be probably preventable which is consistent with Verma et al but not consistent with findings of Gohel et al and Lihite et al. .12,21 $^{1,21}$

\section{CONCLUSIONS}

The study showed that a number of drugs cause dermatological ADRs. These ADRs vary in their appearance, duration, causality, severity, and preventability.

\section{ACKNOWLEDGEMENTS}

Authors would like to thanks Prof. K.C. Saikia, Principalcum-Chief Superintendent, Gauhati Medical College and Hospital, Prof. (Mrs.) Mangala Lahkar, Professor and Head, Department of Pharmacology, GMCH, Dr. Arijit Dutta, Dr. Biswajit Aich, Dr. Atifa Ahmed, Dr. Bidyut Banerjee, Dr. Chimi Handique, Dr. Karishma Adhikari for their sincere co-operation and help and providing me with the zeal and enthusiasm during the course of their study.

\section{Funding: No funding sources}

Conflict of interest: None declared

Ethical approval: The study was approved by the Institutional Ethics Committee, Gauhati Medical College and Hospital (approval no. MC/233/2013/106)

\section{REFERENCES}

1. Gohel D, Bhatt SK, Malhotra S. Evaluation of dermatological adverse drug reaction in the outpatient department of dermatology at a tertiary care hospital. Indian Journal of Pharmacy Practice. 2014;7(3):42-9.

2. Sudershan V, Siddiqua S, Aruna D, Manmohan, Ramesh S, Yasmeen N. Cutaneous adverse drug reactions in a tertiary care hospital. Der Pharmacia Lettre. 2011;3(6):210-7.

3. Valeyrie-Allanore L, Sassolas B, Roujeau JC. Druginduced skin, nail and hair disorders. Drug Saf. 2007;30:1011-30.

4. Patel TK, Thakkar SJ, Sharma DC. Cutaneous adverse drug reactions in Indian population: a systematic review. Indian Dermatol Online J. 2014; 5(Suppl 2):S76-S86.

5. Grover S. Severe cutaneous adverse reactions. Indian Journal of Dermatology, Venereology, and Leprology. 2011;77(1):3-6.

6. Chatterjee S, Ghosh AP, Barbuiya J, Der SK. Adverse cutaneous drug reaction: a one year survey of a dermatology outpatient clinic of a tertiary care hospital. Indian J Pharmacol. 2006;36(6):429-31.

7. Crowson AN, Brown TJ, Magro CM. Progress in the understanding of the pathology and pathogenesis of cutaneous drug eruptions. Am J Clin Dermatol. 2003;4:407-28.

8. Wolkenstein P, Revuz J. Drug-induced severe skin reactions. Drug Safety. 1995;13:56-68.

9. Naranjo CA, Busto U, Sellers EM, Sandor P, Ruiz I, Roberts EA, et al. A method for estimating the probability of adverse drug reactions. Clin Pharmacol Ther. 1981;30:239-45.

10. Hartwig SC, Siegel J, Schneider PJ. Preventability and severity assessment in reporting adverse drug reactions. Am J Hosp Pharm. 1992;49:2229-32.

11. Schumock GT, Thornton JP. Focusing on the preventability of adverse drug reactions. Hosp Pharm. 1992;27:538.

12. Verma R, Tiwari S, Gupta CM, Verma N. Cutaneous adverse drug reactions-a study of clinical patterns, causality, severity and preventability. IOSR Journal of Dental and Medical Sciences (IOSR-JDMS). 2014;13(7):2279-0861.

13. Pudukadan D, Thappa DM. Adverse cutaneous drug reactions: clinical pattern and causative agents in a tertiary care center in South India. Indian J Dermatol Venereal Leprol. 2004;70:20-4.

14. Chatterjee S, Ghosh AP, Barbhuiya J, Dey SK. Adverse cutaneous drug reaction: a one year survey at a dermatology outpatient clinical of a tertiary care hospital. Indian J Pharmacol. 2006;38:429-31.

15. Patel RM, Marfatia YS. Clinical study of cutaneous drug eruptions in 200 patients. Indian J Dermatol Venereol Leprol. 2008;74:80.

16. Sharma VK, Sethuraman G, Kumar B. Cutaneous adverse drug reactions: clinical pattern and causative agents: a six-year series from Chandigarh. India $\mathbf{J}$ Postgrad Med. 2001;47:95-9.

17. Jelvehgari M, Azimi H, Montazam H. Prevalence of cutaneous drug eruption in hospitalized patients: a report from sina hospital of Tabriz. Iranian Journal of Dermatology. 2009;12(1):16-9. 
18. Pudukada D, Thappa DM. Adverse cutaneous drug reactions: clinical pattern and causative agents in a tertiary care center in South India. Indian J Dermatol Venereol Leprol. 2004;70(1):20-4.

19. Anjaneyan G, Gupta R, Vora R. Clinical study of adverse cutaneous drug reactions at a rural based tertiary care centre in Gujarat. National Journal of Physiology, Pharmacy and Pharmacology. 2013;3(2):129-36.
20. Mokhtari F, Nikyar Z, Naeini BA, Esfahani AA, Rahmani S. Adverse cutaneous drug reactions: eight year assessment in hospitalized patients. Journal of Research in Medical Sciences: The Official Journal of Isfahan University of Medical Sciences. 2014;19(8):720-5.

21. Lihite RJ, Lahkar M. A study on cutaneous adverse drug reactions in ADR monitoring centre of tertiary care hospital, Guwahati. Journal of Applied Pharmaceutical Science. 2013;(3):78-81.

Cite this article as: Borah A, Lahkar M, Singha B, Lihite RJ, Hazarika D. To study the pattern of suspected adverse drug reactions in patients coming to the department of dermatology in Gauhati Medical College and Hospital, Guwahati, Assam, India. Int J Basic Clin Pharmacol 2016;5:1655-9. 